\title{
Analisis Faktor-Faktor Yang Berpengaruh Dalam Pemilihan Lokasi Relokasi Pedagang Kaki Lima di Kawasan Pasar Pagi, Kota Samarinda
}

\author{
Analysis of Factors That Influenced the Selection of The Location of Street \\ Vendor Relocation in the Pasar Pagi Area, Samarinda City
}

\author{
Kristia Liendika Arruan Minanga Demas ${ }^{a *}$, Ajeng Nugrahaning Dewanti ${ }^{\mathrm{b}}$ \\ ${ }^{a}$ Institut Teknologi Kalimantan, Balikpapan, Indonesia \\ ${ }^{b}$ Institut Teknologi Kalimantan, Balikpapan, Indonesia
}

\begin{abstract}
Abstrak
Sesuai dengan program prioritas RPJMD Kota Samarinda tahun 2016-2021 dalam penataan Pedagang Kaki Lima di kawasan perdagangan dan jasa, bentuk usaha yang sudah diterapkan dalam upaya penataan Pedagang Kaki Lima yaitu di kawasan Pasar Pagi dengan melakukan penertiban dan penggusuran. Namun yang menjadi permasalahan adalah Pedagang Kaki Lima yang telah digusur terus kembali pada lokasi yang sama untuk berdagang. Sehingga sebagai salah satu langkah awal dalam penataan maka perlu adanya identifikasi karakteristik PKL serta analisis faktor- faktor yang berpengaruh dalam pemilihan lokasi untuk relokasi bagi Pedagang Kaki Lima di kawasan Pasar Pagi. Metode yang digunakan adalah statistik deskrptif dan analisis Delphi. Hasil menunjukkan bahwa karakteristik PKL di Pasar Pagi teridentifikasi dalam tiga kelompok yang dibagi berdasarkan jenis dagangan yaitu Kelompok I : Makanan/Minuman Siap Saji; Kelompok II : Non-Makanan; Kelompok III : Jasa. Faktor-faktor yang berpengaruh dalam penataan pedagang kaki lima berdasarkan perspektif stakeholders yaitu (1) Sirkulas; (2) Dekat Permukiman; (3) Aksesibilitas; (4) Ekspansi; (5) Lahan Parkir; (6) Jaringan Listrik; (7) Jaringan Air Bersih; (8) Jaringan Limbah; (9) Lingkungan; (10) Visibilitas; (11) Fungsi Jalan; (12) Akses Pejalan Kaki dan (13) Kebijakan Tata Ruang.
\end{abstract}

Kata kunci: Faktor; Karakteristik; Pedagang Kaki Lima.

\begin{abstract}
In accordance with the priority program RPJMD Samarinda city in 2016-2021 in the arrangement of Street Vendors in the area of trade and services, the form of business that has been applied in the efforts to organize Street Vendors in the Pasar Pagi area by conducting control and eviction. But the problem is because the displaced Street Vendors continue to return to the same location to trade. So as one of the first steps in the arrangement, there needs to be identification of pkl characteristics as well as analysis of factors that are influential in the selection of locations for relocation for Street Vendors in the Pasar Pagi area. The methods used are descriptive statistics and Delphi analysis. The results showed that the characteristics of street vendors in the Pasar Pagi were identified in three groups divided by the type of merchandise, namely Group I : Meals/Beverages; Group II : Non-Food; Group III: Services. Factors that influence the arrangement of street vendors based on the perspective of stakeholders namely (1) Circular; (2) Near Settlements; (3) Accessibility; (4) Expansion; (5) Parking Lot; (6) Electricity Network; (7) Clean Water Network; (8) Waste Network; (9) Environment; (10) Visibility; (11) Road Function; (12) Pedestrian Access and (13) Spatial Policy.
\end{abstract}

Keyword: Factors; Characteristics; Street Vendor.

\footnotetext{
* First author. Kristia Liendika Arruan Minanga Demas.

E-mail address: krstlndk@gmail.com
} 


\section{Pendahuluan}

Kota Samarinda merupakan Ibukota Provinsi Kalimantan Timur yang sangat aktif dalam sektor perekonomian dan tidak terlepas dari aktivitas Pedagang Kaki Lima. Pusat- pusat Pedagang Kaki Lima di Kota Samarinda umumnya berada pada kawasan yang ramai dikunjungi masyarakat salah satunya adalah kawasan perdagangan dan jasa yaitu pasar tradisional Pasar Pagi di Kelurahan Pasar Pagi, Kecamatan Samarinda Kota. Pasar Pagi merupakan pasar tertua di Kota Samarinda. Pada awalnya, posisi dari Pasar Pagi dibangun tepat di pinggir sungai Mahakam. Namun seiring berjalannya waktu dan berkembangnya penataan Kota Samarinda, letak Pasar Pagi dipindahkan menjauh dari tepi sungai Mahakam karena daerah sempadan tersebut telah ditetapkan sebagai jalur hijau (RPJMD Kota Samarinda, 2016). Letak Pasar Pagi yang strategis menjadikan pasar ini sebagai entry-point dalam pendistribusian barang ke wilayah lain yang ada di Kalimantan Timur. Sebagai pasar pertama yang ada di Kota Samarinda, menjadikan Pasar Pagi sebagai tempat yang lengkap dalam penyediaan berbakai kebutuhan primer, sekunder dan tersier (Dinas Perdagangan Kota Samarinda, 2021).

Pedagang Kaki Lima pada Kawasan Pasar Pagi aktif berdagang mulai dari pagi hingga sore hari dan mengundang keramaian pada peak hour. Sesuai dengan agenda penanganan dan penataan PKL yang masuk dalam salah satu agenda prioritas RPJMD Kota Samarinda 20172021 yaitu melakukan penataan PKL dan sektor informal lainnya pada kawasan perdagangan, bentuk upaya yang telah dilakukan oleh pihak berwenang adalah dengan menerapkan kegiatan penertiban dan pembubaran PKL yang berdagang pada sekitar Kawasan Pasar Pagi. Namun berdasarkan survey pendahuluan yang telah dilakukan diketahui bahwa terdapat fenomena dimana PKL yang telah digusur terus kembali berjualan pada kawasan yang sama. Diketahui bahwa hal yang mendasari terjadinya fenomena tersebut adalah karena setelah melakukan penggusuran, tidak ada tindak lanjut lebih jauh dari Pemerintah kepada PKL yang tergusur. Sedangkan dari PKL mengharapkan adanya pengarahan untuk lokasi berjualan yang sesuai, dengan kata lain Pemerintah tidak menyediakan lokasi pasca penggusuran PKL di Kawasan Pasar Pagi. Sehingga diketahui bahwa upaya pembubaran dan penertiban tidak memberikan solusi dalam penataan Pedagang Kaki Lima di kawasan Pasar Pagi. Sehingga sebagai salah satu langkah awal dalam penataan maka perlu adanya identifikasi karakteristik PKL serta analisis faktor- faktor yang berpengaruh dalam pemilihan lokasi untuk relokasi bagi Pedagang Kaki Lima di kawasan Pasar Pagi.

\section{Metode}

Jenis penelitian yang digunakan adalah penelitian kualitatif yang bersifat eksploratif dengan model penelitian studi kasus. Metode penelitian yang digunakan adalah analisis Delphi melalui stakeholders yang terdiri dari Bappeda Kota Samarinda, Dinas PUPR Kota Samarinda dan Dinas Perdagangan Kota Samarinda. Penelitian berikut menggunakan data primer dimana sumber data untuk mengidentifikasi karakteristik adalah dengan wawancara dan observasi kepada seluruh populasi PKL di kawasan Pasar Pagi yaitu sebanyak 116 Pedagang. Sedangkan untuk menganalisis faktor- faktor yang berpengaruh menggunakan metode wawancara kepada stakeholders yang bersangkutan.

\section{Kajian literatur}

\subsection{Pedagang Kaki Lima}

Budi (2006) memberikan didefinisikan bahwa Pedagang Kaki Lima (PKL) sebagai sekelompok orang yang menawarkan barang dan jasa untuk dijual pada ruang publik, terutama dipinggir jalan dan trotoar. Sedangkan menurut Mulyanto (2007), PKL merupakan usaha kecil yang berorientasi pada laba atau profit layaknya sebuah kewirausahaan. PKL mempunyai cara tersendiri dalam mengelola usahanya agar mendapatkan keuntungan. PKL menjadi manajer tunggal yang menagani usahanya mulai dari perencanaan usaha, menggerakan usaha sekaligus mengontrol atau mengendalikan usahanya, padahal fungsi- fungsi manajemen tersebut jarang atau bahkan tidak pernah mereka dapatkan dari pendidikan formal. 
PKL menjadi salah satu sektor yang paling menonjol di sektor informal yang selalu bergantung pada sektor formal dan menjadi alternatif ketika orang tidak dapat masuk/ bergabung ke sektor formal dan mereka harus memenuhi kebutuhan mereka (Hapsari, 2019). Sehingga PKL dapat diartikan sebagai salah satu kelompok sektor informal yang lokasi usahanya dikeramaian umum seperti trotoar dipinggir jalan, kawasan perdagangan, ataupun sekolah. Biasanya tidak memiliki izin usaha dan aktivitas yang dilakukan cenderung berpindahpindah serta memiliki modal yang terbatas. Pedagang Kaki Lima timbul karena adanya efek dari proses urbanisasi dan kurangnya lapangan pekerjaan formal yang ada yang bisa menampung para pekerja yang memutuskan untuk bekerja pada sektor informal khususnya menjadi Pedagang Kaki Lima.

\subsection{Karakteristik Pedagang Kaki Lima}

Pedagang kaki lima memiliki karakteristik tersendiri seperti yang diungkapkan oleh Simanjutak dalam Hapsari (2019) yang menjelaskan karakteristik pedagang kaki lima meliputi (1) kegiatan usaha cenderung sederhana dan sistem kerjasama serta pembagian posisi kerja lebih fleksibel, (2) pada umumnya skala, modal, dan pendapatan berskala kecil. (3) tidak memiliki izin usaha. Sebagai wujud nyata dari fenomena sektor informal, secara umum karakteristik yang dimiliki oleh Pedagang Kaki Lima sangat dekat dengan karakteristik dari sektor informal secara keseluruhan. Dalam konteks yang lebih detail, Mc. Gee dan Yeung dalam Widjajanti (2018) mengungkapkan karakteristik dari Pedagang Kaki Lima dapat dikategorikan dalam beberapa aspek yaitu jenis barang atau jasa yang dijual, pola pelayanan dan sifat pelayanan, pola penyebaran, karakteristik lokasi berdagang, bentuk sarana fisik berdagang dan pola pengelolaan aktivitas Pedagang Kaki Lima. Berdasarkan definisi dan karakteristik PKL yang telah dijabarkan pada tinjauan teori, didapatkan variabel penelitian untuk menganalisis karakteristik PKL di Kawasan Perdagangan Pasar Pagi adalah sebagai berikut.

1. Jenis sarana

2. Jenis Dagangan atau Jasa

3. Sifat Pelayanan

4. Luas Lapak

5. Utilitas Penunjang

6. Lokasi Berjualan

7. Kondisi Lingkungan Keramaian

8. Jarak Tempat Tinggal

\subsection{Faktor-faktor pemilihan lokasi relokasi Pedagang Kaki Limau}

Faktor-faktor merupakan instrumen yang berpengaruh terhadap suatu kodisi maupun usaha, yang mana jika ditinjau dari kebutuhan penelitian, peranan faktor-faktor sebagai instrumen yang mempengaruhi pemecahan masalah pada objek penelitian. Faktor-faktor penataan Pedagang Kaki Lima perlu dikaji dan diindentifikasi faktor-faktor berpengaruhnya sebagai salah satu masukan dalam perumusan kriteria penataan Pedagang Kaki Lima berdasarkan karakteristik pedagang di kawasan Pasar Pagi Kelurahan Pasar Pagi Kota Samarinda. Dimana faktor-faktor yang dikaji mencakup prinsip pemilihan lokasi, faktor penentu lokasi berdagang, dan faktor dalam penataan Pedagang Kaki Lima. Berdasarkan penelitian yang diangkat oleh Fajrin dan Rahmawati (2016); Fandi Tjiptono (2002); Novelia (2015); dan Witjaksono (2005), ditemukan faktor- faktor yang berpengaruh dalam penataan Pedagang Kaki Lima sebagai berikut :

1. Sirkulasi

2. Fungsi jalan

3. Dekat pusat kegiatan formall

4. Dekat permukiman

5. Jumlah penduduk

6. Aksesibilitas

7. Ekspansi

8. Lahan parkir
9. Dekat lahan parkir

10. Jaringan listrik

11. Jaringan air bersih

12. Jaringan limbah

13. Lingkungan

14. Visibilitas

15. Jarak dengan bahan baku 


\section{Hasil dan Pembahasan}

Pedagang Kaki Lima yang masuk dalam objek penelitian adalah PKL yang berdagang pada koridor jalan dan trotoar di sekitar Pasar Pagi. Pasar Pagi merupakan pasar tradisional tertua di Kota Samarinda. Secara administrasi diketahui bahwa pasar tradisional Pasar Pagi masuk dalam wilayah administrasi dari Kelurahan Pasar Pagi. Jika dilihat berdasarkan lokasi penelitian, maka terdapat batasan-batasan lokasi penelitian sebagai berikut.

Sebelah Utara : Jalan Jendral Sudirman, Kelurahan Pasar Pagi

Sebelah Selatan : Jalan Tumenggung Suropati, Kelurahan Pasar Pagi

Sebelah Timur : Jalan KH. Khalid, Kelurahan Pasar Pagi

Sebelah Barat : Gang 2, Jalan Garah Mada, Kelurahan Pasar Pgi

Secara keseluruhan total jumlah PKL yang tercatat pada data Persebaran Pedagang Kaki Lima dari Satpol PP Kota Samarinda adalah sebanyak 109 orang. Namun berdasarkan survey yang telah dilakukan terdapat 116 PKL yang tersebar di kawasan Pasar Pagi. Berikut merupakan peta wilayah penelitian sebagai berikut.

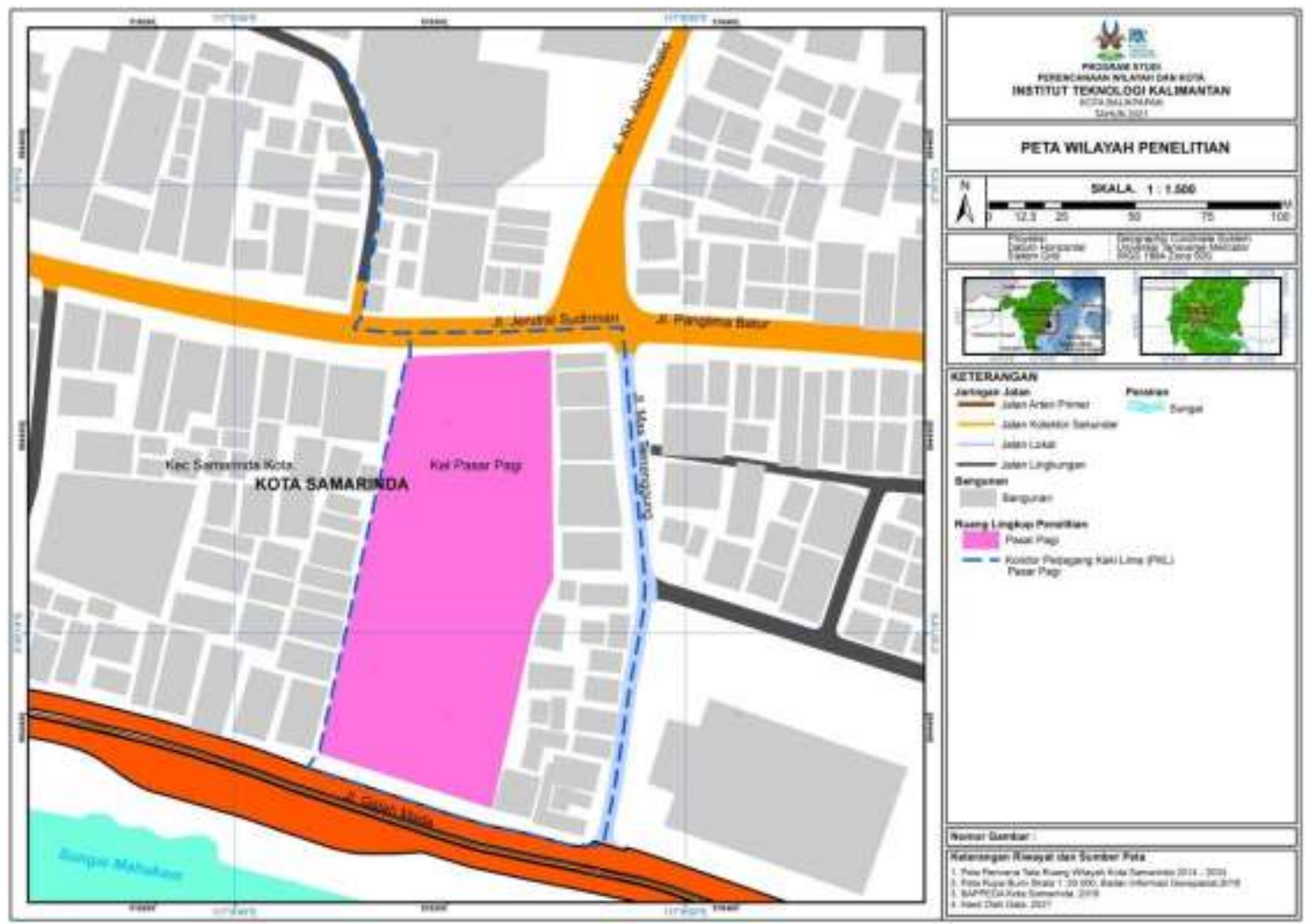

Gambar 1. Peta Wilayah Penelitian (Penulis, 2021)

\subsection{Karakteristik Pedagang Kaki Lima di Kawasan Pasar Pagi}

Diketahui bahwa karakteristik PKL terbagi ke dalam 3 (tiga) kelompok yang ditentukan berdasarkan jenis dagangannya. Penentuan pembagian kelompok karakteristik berdasarkan jenis makanan dipengaruhi oleh kedudukan variabel jenis dagangan sebagai variabel yang mempengaruhi variabel lainnya. Menurut Marshush (2013) tipe karakteristik pedagang kaki lima ditentukan berdasarkan jenis dagangannya karena jenis dagangan merupakan acuan pedagang untuk menentukan variabel dari karakteristik pedagang lainnya seperti jenis sarana, waktu aktivitas, loksi berdagang dan lainnya. Selain itu pula jenis dagangan merupakan variabel yang paling sedikit kemungkinan akan terpengaruh atau berubah jika terjadi kegiatan relokasi PKL menuju lokasi baru. Selanjutnya berikut disajikan tabel temuan karakteristik PKL berdasarkan kelompok- kelompok sebagai berikut. 
Tabel 1. Karakteristik PKL di Kawasan Pasar Pagi (Analisis Penulis, 2021)

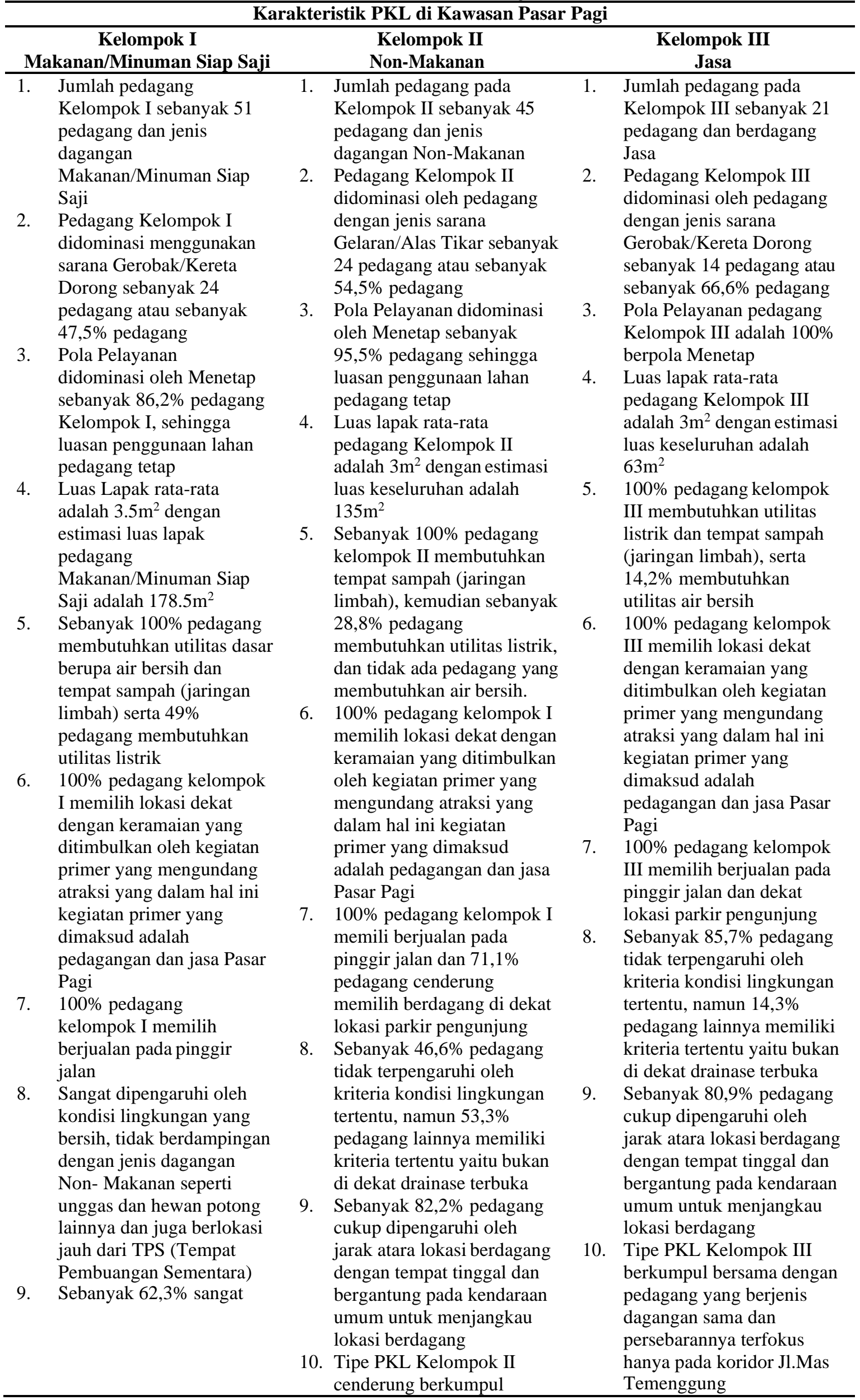




\begin{tabular}{ccc}
\hline & Karakteristik PKL di Kawasan Pasar Pagi & \\
\hline \multicolumn{1}{c}{ Kelompok I } & \multicolumn{1}{c}{ Kelompok II } \\
Non-Makanan & Kelompok III \\
Makanan/Minuman Siap Saji & Jasa \\
\hline dipengaruhi oleh jarak & bersama dengan pedagang & \\
atara lokasi berdagang & yang berjenis dagangan \\
dengan tempat tinggal & sama namun persebarannya \\
dan bergantung pada & cenderung terfokus pada \\
transportasi kendaraan & koridor Jl.Mas Temenggung \\
umum sebagai sarana & \\
menjangkau lokasi & \\
berdagang & \\
10. Tipe PKL Kelompok 1 & \\
cenderung berkumpul & \\
bersama dengan & \\
pedagang yang berjenis & \\
dagangan sama namun & \\
tidak terpusat pada satu & \\
titik melainkan menyebar & \\
mengelilingi kawasan & \\
Pasar Pagi &
\end{tabular}

Diketahui bahwa dalam tiap kelompok yang terbentuk memiliki perbedaan karakteristik tergantung dari jenis dagangan pedagang tersebut. Namun ada pula karakteristik yang sama yang dimiliki oleh tiap kelompok pedagang kaki lima di kawasan Pasar Pagi yaitu diketahui bahwa seluruh pedagang memilih berdagang pada lokasi dekat dengan keramaian yang ditimbulkan oleh kegiatan primer yang mengundang atraksi yang dalam hal ini kegiatan primer yang dimaksud adalah pedagangan dan jasa Pasar Pagi dan memilih berjualan pada area luas pasar dan bukan dalam pasar. Hal ini karena pada prinsipnya PKL memiliki kecenderungan untuk mendekati konsumen. Berikut disajikan peta persebarang PKL di kawasan Pasar Pagi berdasarkan jenis dagangan/kelompok yang terbentuk.
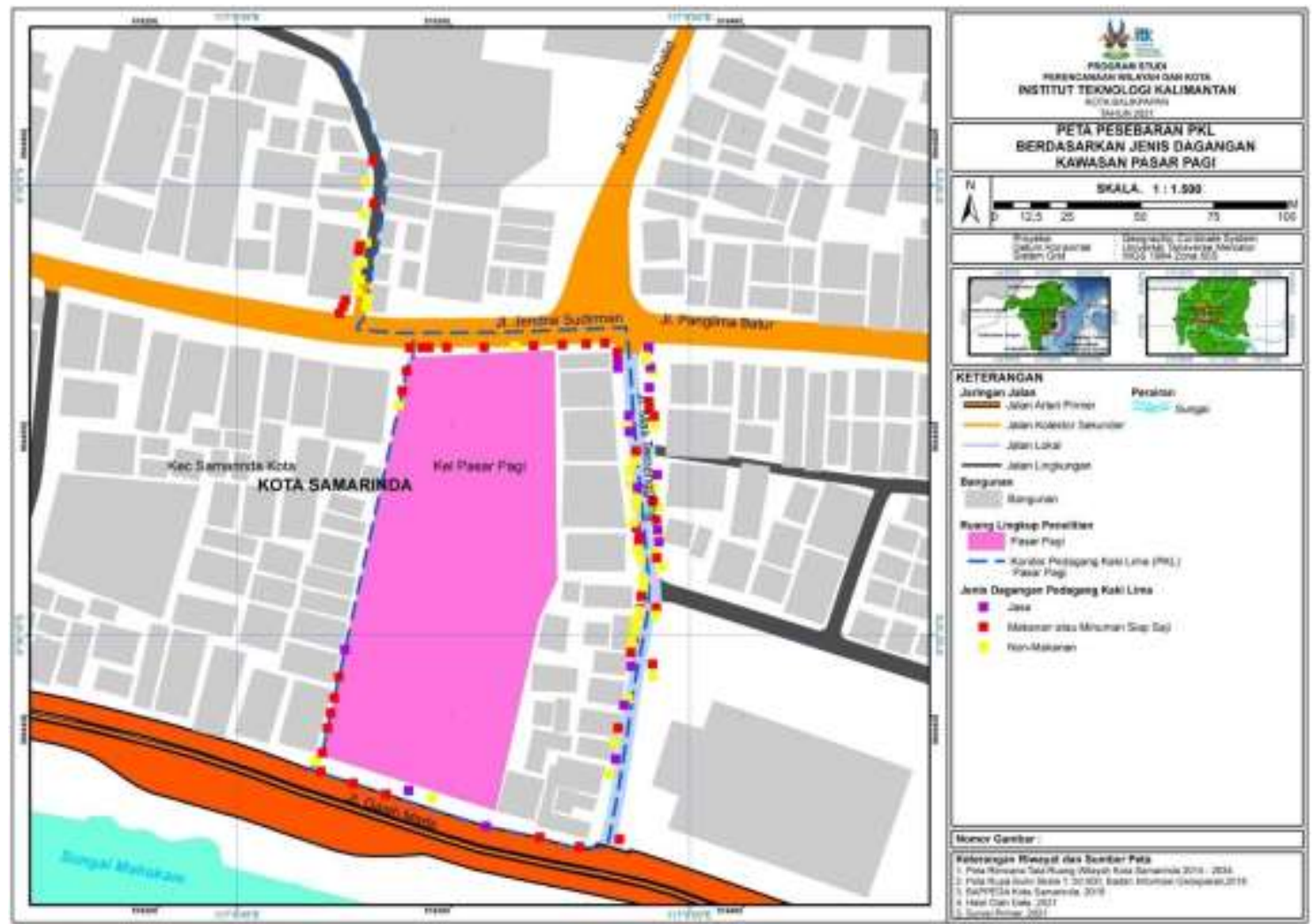

Gambar 2. Peta Persebaran PKL Berdasarka Jenis Dagangan/Kelompok (Penulis, 2021) 


\subsection{Faktor-Faktor Yang Berpengaruh Dalam Pemilihan Lokasi Relokasi Bagi PKL di Kawasan Pasar Pagi}

Dalam menganalisis faktor-faktor yang berpengaruh dalam penataan Pedagang Kaki Lima di kawasan Pasar Pagi dengan tujuan untuk mengetahui faktor-faktor yang berpengaruh terhadap penataan Pedagang Kaki Lima, maka digunakan alat analisis yaitu analisis Delphi untuk mencapai tujuan pada sasaran dua. Diketahui bahwa dalam pengambilan data, peneliti memastikan bahwa stakeholders memahami terlebih dahulu terkait dengan karakteristik PKL di kawasan Pasar Pagi sehingga faktor yang dipilih merupakan faktor yang bennar berpengaruh pada PKL di kawasan Pasar Pagi.

Berikut disajikan hasil tabel analisis Delphi sebagai berikut.

Tabel 2. Analisis Delphi Iterasi I (Analisis Penulis, 2021)

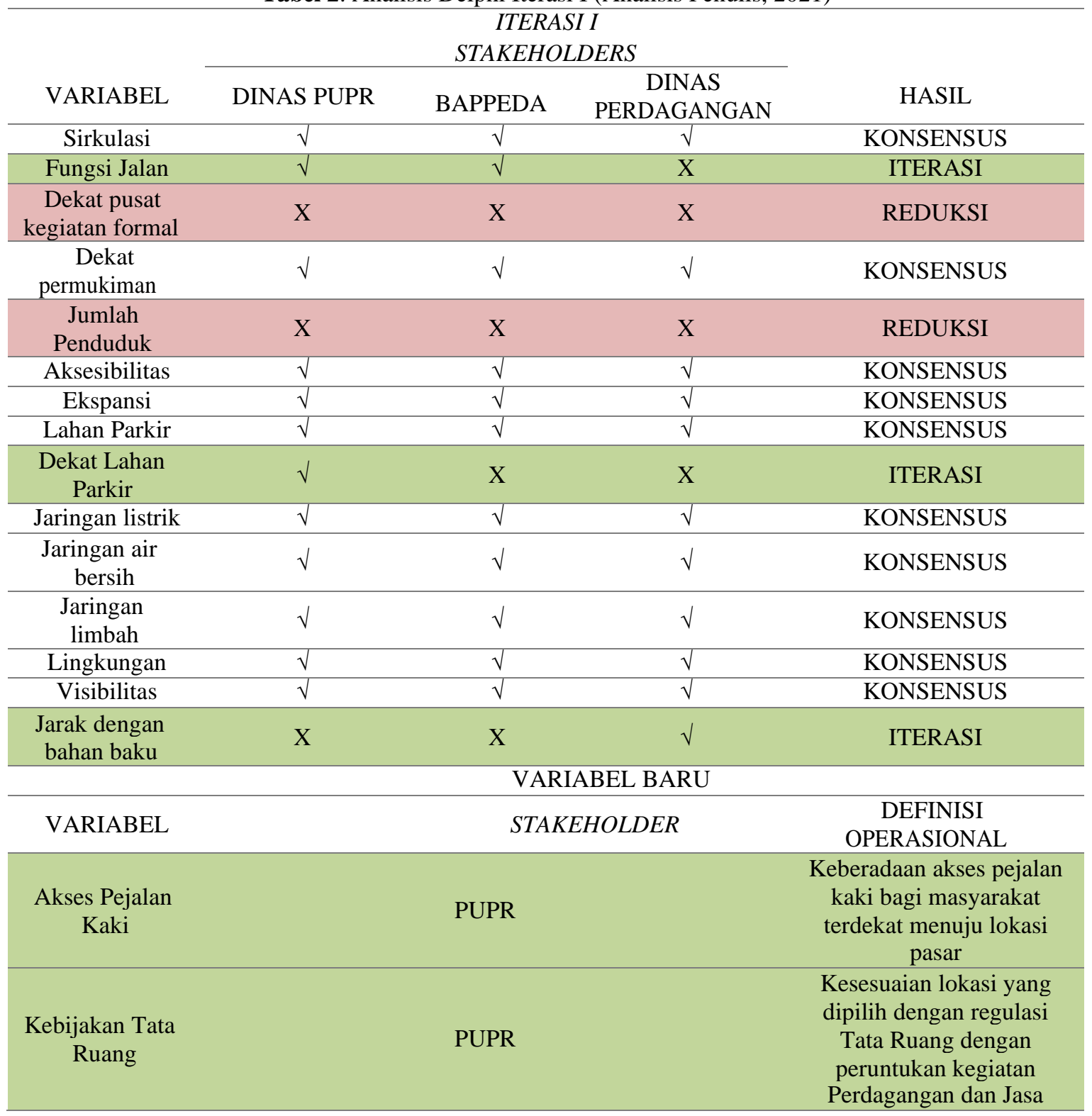

Pada analisis putaran pertama didapatkan bahwa terdapat 2 (dua) variabel yang terreduksi yaitu variable Dekat Pusat Kegiatan Formal dan Jumlah Penduduk, kemudian terdapat 10 (sepuluh) variabel konsensus diantaranya variabel Sirkulas; Dekat Permukiman; Aksesibilitas; Ekspansi; Lahan Parkir; Jaringan Listrik; Jaringan Air Bersih; Jaringan Limbah; Lingkungan; dan Visibilitas. Kemudian diketahui pula variabel yang perlu ditanyakan kembali (iterasi kedua) yaitu diantaranya variabel Fungsi Jalan; Dekat Lahan Parkir; dan Jarak Dengan Bahan Baku. Selain itu terdapat juga variabel tambahan dari stakeholder 1 yaitu Instansi PUPR sebanyak 2 (dua) variabel diantaranya variabel Akses Pejalan Kaki dan Kebijakan Tata Ruang. Kedua variabel baru tersebut akan diinput ke dalam variabel proses iterasi kedua. Berikut disajikan tabel iterasi kedua sebagai berikut. 
Tabel 3. Analisis Delphi Iterasi II (Analisis Penulis, 2021)

ITERASI II

STAKEHOLDERS

\begin{tabular}{ccccc}
\cline { 2 - 4 } VARIABEL & DINAS PUPR & BAPPEDA & DINAS & HARDAGANGAN \\
\hline $\begin{array}{c}\text { Fungsi Jalan } \\
\begin{array}{c}\text { Dekat Lahan } \\
\text { Parkir }\end{array}\end{array}$ & $\sqrt{ }$ & $\sqrt{ }$ & $\sqrt{ }$ & KONSENSUS \\
\hline $\begin{array}{c}\text { Jarak dengan } \\
\text { bahan baku }\end{array}$ & $\mathrm{X}$ & $\mathrm{X}$ & $\mathrm{X}$ & REDUKSI \\
\hline $\begin{array}{c}\text { Akses Pejalan } \\
\text { Kaki }\end{array}$ & $\sqrt{ }$ & $\sqrt{ }$ & $\sqrt{ }$ & REDUKSI \\
\hline $\begin{array}{c}\text { Kebijakan Tata } \\
\text { Ruang }\end{array}$ & $\sqrt{ }$ & $\sqrt{ }$ & $\sqrt{ }$ & KONSENSUS \\
\hline
\end{tabular}

Berdasarkan hasil iterasi di atas diketahui bahwa iterasi yang dilakukan adalah sebanyak dua putaran iterasi. Dari hasil iterasi pertama, kemudian disusun kembali untuk melakukan konfirmasi lanjutan terkait variabel iterasi dan variabel baru dengan susunan variabel diantaranya variabel Fungsi Jalan; Dekat Lahan Parkir; Jarak Dengan Bahan Baku; Akses Pejalan Kaki dan Kebijakan Tata Ruang. Kemudian dari iterasi kedua didapatkan hasil yaitu untuk variabel tereduksi sebanyak 2 (dua) variabel yaitu Jarak Dengan Bahan Baku dan Dekat Lahan Parkir. Sedangkan untuk variabel baru yang ditermukan pada iterasi pertama yaitu Akses Pejalan Kaki dan Kebijakan Tata Ruang yang merupakan masukan dari stakeholder 1 diketahui telah konsensus atau disepakati bersama oleh seluruh stakeholders sehingga variabel baru tersebut dikatakan valid menjadi faktor penataan PKL. Sehingga untuk variabel konsensus diketahui sebagai berikut Fungsi Jalan; Dekat Lahan Parkir; Akses Pejalan Kaki dan Kebijakan Tata. Dan tidak ditemukan variabel iterasi dan variabel baru.

Sehingga dari analisis berikut dapat disimpulkan bahwa faktor-faktor yang berpengaruh dalam penataan PKL di kawasan Pasar Pagi adalah variabel-variabel konsensus dari hasil analisis Delphi sebanyak 13 (tiga belas) variabel diantaranya variabel Sirkulas; Dekat Permukiman; Aksesibilitas; Ekspansi; Lahan Parkir; Jaringan Listrik; Jaringan Air Bersih; Jaringan Limbah; Lingkungan; Visibilitas; Fungsi Jalan; Akses Pejalan Kaki dan Kebijakan Tata Ruang. Dari 13 (tiga belas) faktor tersebut diketahui bahwa terdapat 2 variabel yang merupakan variabel baru yaitu variable Akses Pejalan Kaki dan Kebijakan Tata Ruang yang merupakan hasil masukan dari stakeholder terkait yaitu dari instansi Dinas PUPR Kota Samarinda.

\section{Kesimpulan}

Berdasarkan penelitian yang telah dilakukan didapatkan keismpulan bahwa karakteristik pedagang kaki lima di kawasan Pasar Pagi dikategorikan ke dalam 3 (tiga) kelompok yang dibagi berdasarkan jenis dagagan pedagang yang terdiri dari Kelompok I : Makanan/Minuman Siap Saji, Kelompok II : Non-Makanan, dan Kelompok III : Jasa. Dimana karakteristik yang terbentuk berbeda-beda dan bergantung pada jenis dagangan yang diperdagangkan. Kemudian untuk temuan analisis faktor yang berpengaruh dalam pemilihan lokasi relokasi pedagang kaki lima di kawasan pasar pagi yang dianalisis menggunakan metode Delphi menghasilkan temuan yaitu faktor Sirkulas; Dekat Permukiman; Aksesibilitas; Ekspansi; Lahan Parkir; Jaringan Listrik; Jaringan Air Bersih; Jaringan Limbah; Lingkungan; Visibilitas; Fungsi Jalan; Akses Pejalan Kaki dan Kebijakan Tata Ruang. Diketahui bahwa terdapat faktor baru yang ditambahkan oleh stakeholders untuk melengkapi faktor pemilihan lokasi menjadi sesuai dengan karakteristik PKL Pasar Pagi. 


\section{Referensi}

Budi, Ari Sulistiyo. (2006). Kajian Lokasi Pedagang Kaki Lima Berdasarkan Preferensi PKL Serta Persepsi Masyarakat Sekitar di Kota Pemalang. Tesis. Magister Pembangunan Wilayah dan Kota. Semang:Universitas Diponegoro.

Fajrin, Akhmad Raditya Maulana \& Dian Rahmawati. (2016). Faktor-faktor yang Berpengaruh dalam Penataan Pedagang Kaki Lima (PKL) pada Koridor Jalan Pasar Besar Kota Malang. Jurnal Teknik ITS Vol. 5, No. 1, ISSN: 2337-3539.

Fandy Tjiptono dan Anastasia Diana. (2002). Total Quality Manajemen Edisi Revisi. Yogyakarta. Andy Offset.

Hapsari, K. C. (2019). Pedagang Bermotor: Karakteristik Baru Pedagang Kaki Lima di Kawasan Pendidikan Tembalang, Semarang. Jurnal Riptek, 11(1), 57-66.

Marshush, U. H., \& Kurniawati, W. (2013). Kajian Karakteristik Pedagang Kaki Lima (Pkl) yang Mempengaruhi Terganggunya Sirkulasi Lalulintas di Jalan Utama Perumahan Bumi Tlogosari Semarang. Ruang, 1(1), 91-100.

Mulyanto. (2007). "Pengaruh Motivasi dan Kemampuan Manajerial Terhadap Kinerja Usaha Pedagang Kaki Lima Menetap (Suatu Survai pada Pusat Perdagangan dan Wisata Di Kota Surakarta)", dalam Jurnal BENEFIT, Volume 11, Nomor 1, Juni 2007, Fakultas Ekonomi Universitas Muhammadiyah Surabaya.

Novelia, Adinda Sukma dan Sardjito. (2016). Kriteria Penentuan Lokasi Perdagang Kaki Lima Berdasarkan Preferensi Pedagangnya di Kawasan Perkotaan Sidoarjo. Jurnal Teknik ITS Vol. 4, No. 1, 2015. ISSN: 2337-3539. Surabaya.

RPIJM. (2016). Laporan Final : Bantuan Teknis Pendampingan Penyusunan Dokumen RPIJM Kota Samarinda Tahun Anggaran 2016. Pemerintah Kota Samarinda : Samarinda.

Widjajanti, R. (2018). Karakteristik Aktivitas Pedagang Kaki Lima di Ruang Publik Kota pada Taman Tirto Agung, Kecamatan Banyumanik, Semarang Activity Characteristics of Street Vendors in Urban Public Spaces at Taman Tirto Agung, Banyumanik District, Semarang. Ruang, 4(2), 185194.

Witjaksono, Agung. (2005). Bagaimana Kegiatan Ekonomi Informal (Pedagang Kaki Lima) Dapat Mendukung Perkembangan Kota, Prosiding Seminar Nasional Pembangunan Lingkungan Perkotaan di Indonesia. Jakarta: Penerbit Universitas Trisakti Press, Cetakan Pertama. 